\title{
\begin{tabular}{lccl}
\hline PKS & REVISTA DE GEOGRAFIA & OJS \\
$\begin{array}{lcc}\text { PUBLIC } \\
\text { KNOWLEGG } \\
\text { PROJECT }\end{array}$ & heCIF://www.revista.ufpe.br/revistageografia & $\begin{array}{l}\text { OPEN } \\
\text { JOURAL } \\
\text { SYSTEMS }\end{array}$ \\
\hline
\end{tabular}
}

\section{A ESSÊNCIA DO ESPAÇO E DO TEMPO}

\author{
Marquessuel Dantas de Souza ${ }^{1}$ \\ ${ }^{1}$ Instituto Federal de São Paulo; Email: marquessuelgf@gmail.com \\ Resenha recebida em 23/08/2015 e aceita em 15/08/2017
}

\begin{abstract}
RESUMO
O presente texto analisa, de forma singular, a essência do espaço e do tempo para os estudos geográficos. Conquanto, são conceitos oriundos da filosofia, por vezes, discutidos à partir da ótica de Friedrich Ratzel, um dos mais influentes geógrafos do mundo. Não obstante, o autor desenvolve suas análises e reflexões traçando argumentos fundamentados em pensamentos de épocas remotas (filosofias de outrora) em relação à época de sua publicação (início do século XX). Decerto, o texto ratzeliano direciona pontos de vistas inovadores referentes ao estudo do espaço e do tempo na geografia.
\end{abstract}

Palavras-chave: Geografia; Espaço; Tempo.

\section{THE ESSENCE OF SPACE AND TIME}

\begin{abstract}
The present text analyzes, in a singular way, the essence of space and time for geographic studies. However, they are concepts from philosophy, sometimes discussed from the perspective of Friedrich Ratzel, one of the most influential geographers in the world. Nevertheless, the author develops his analyzes and reflections by drawing arguments based on thoughts from remote times (philosophies of the past) in relation to the time of his publication (beginning of the 20th century). Certainly, the Ratzelian text directs innovative points of view concerning the study of space and time in geography.
\end{abstract}

Keywords: Geography; Space; Time. 


\section{INTRODUÇÃO ${ }^{1}$}

O texto aqui exposto analisa a essência do espaço e do tempo para os estudos geográficos. Para tanto, o autor traça linhas de pensamentos de épocas remotas à época de sua publicação (início do século XX). É notório observar que o mesmo traz uma contribuição outra no sentido de discutir conceitos tão importantes para a ciência da terra. Não obstante, direciona pontos de vistas inovadores quando do estudo referente ao espaço e ao tempo.

Partindo da mitologia grega, Ratzel simboliza o que considera fundamental àquilo que podemos chamar de "reflexão conceitual" em ralação ao estudo do espaço-tempo. Buscando compreender esta situação Ratzel enfatiza a filosofia pré-socrática relacionado-a com as descobertas mais recentes, referindo-se a tese de Kant. Ademais, vê-se ao longo do texto que Ratzel efetua uma crítica a ideia de espaço vazio e infinito, o mesmo com relação ao tempo. $\mathrm{O}$ mesmo opõe-se a esta concepção. Bem entendido, a presente tradução se volta para 'dois capítulos' de uma obra completa. - Na obra Ratzel retoma um termo bastante difundido na história do pensamento geográfico e cujo mesmo influenciou gerações posteriores, o qual o mesmo o utilizou para fundamentar sua tese: espaço vital (Lebensräume, p. 25)2.

Ao citar alguns autores Ratzel corrobora com a ideia de se estudar outros campos do saber para o desenvolvimento da ciência geográfica e suas ramificações. Alguns dos autores citados condizem que Ratzel os estudou para elaborar e fundamentar toda a obra que dedicou à análise literária e filosófica do espaço e do tempo. Em toda a obra ele faz referência a autores como Darwin, Demócrito, Goethe, Humboldt, Descartes, Hegel, Galileu Galilei, Moritz Wagner, Leibniz, Karl Ritter, Giordano Bruno, Copérnico, Häckel, Werner, Wallace, entre muitos outros, ou melhor, somente para citar os mais conhecidos. Por sua vez, referente à ideia de tempo o próprio Ratzel dedique um capítulo as análises de Hutton, Lamarck, von

\footnotetext{
1 Traduzido do alemão in: RATZEL, Friedrich. Raum und Zeit in Geographie und Geologie. Naturphilosophisch Betrachtungen. (Herausgegeben von Paul Barth) Leipzig: Johann Ambrosius Barth, 1907. 186p. (Natur - und Kulturphilosophisch Bibliotek; Band IV). Espaço e Tempo na Geografia e Geologia: considerações filosóficas naturais. - A obra referida é um trabalho póstumo de Ratzel. Esta reúne as notas do curso proferido por Ratzel no ano de seu falecimento (1904), depois publicadas em livro, editado por Paul Barth, cuja primeira parte trata do "espaço" e a segunda parte da "exigência do tempo no desenvolvimento das ciências". Tradução de Marquessuel Dantas de Souza. Graduado em Geografia. Estudante do Grupo de Pesquisa Geografia, Literatura e Arte (Geoliterart) da USP. (N. T.).

${ }^{2} \mathrm{O}$ estudo detalhado ou profundo sobre a ideia de espaço vital fora discutido primeiramente e em seus pormenores na obra Geografia Política de 1897. Para mais detalhes é possível consultar uma versão original em alemão. Politische Geographie oder die Geographie der Staaten, des Verkehrs und des Krieges. Neudruck der dritten auflage von 1923, durchgesehen und ergänzt von Eugen Oberhummer. Osnabrück: Otto Zeller Verlag, 1974. 626p. Além disso, acrescento que posteriormente o autor se dedicou a um estudo específico sobre o espaço vital. Der Lebensraum. Eine biogeographische Studie. Laupp, Tübingen, 1901, 87p. (N. T.). 
Hoff e Charles Lyell. Embora nos capítulos aqui traduzidos Ratzel tenha mencionados apenas Hesíodo, Heráclito, Schiller, Kant, Rückert, Fleming e Heinrich Noë3 .

Sumariamente observa-se o grau de importância do passado para se compreender o presente, por sua vez, buscando dialogar com vistas no futuro. - Um trabalho de investigação importante para a Geografia, cujo mesmo evidentemente torna-se material de referência à questão espacial e temporal na Geografia. Escritos ricos em detalhes que promovem reflexões profundas para se pensar qual a essência, o significado do espaço e do tempo. De certo, o estudo não se limita à Geografia, vê-se que o autor amplia o leque de conhecimentos quando nos conduz a avançar sobre o que o espaço e o tempo oferecem ao geógrafo.

Neste escrito, Ratzel direciona ou conduz seu olhar a contribuir para com o desenvolvimento da Geografia Científica. - Espaço e tempo, conceitos inerentes à Geografia. Com efeito, o geógrafo alemão os formula sabiamente a favorecer outros debates no que tange as mesmas concepções.

\section{A ESSÊNCIA DO ESPAÇO ${ }^{4}$}

O significado mais abrangente da palavra espaço é algo como 'amplo' (extenso), 'vazio'. Tão como sempre ocorre em todas as línguas germânicas. Temos no gótico - rûm um substantivo no sentido de lugar, área; e um adjetivo no sentido de largo, vasto. No Altnordischen $^{5}$ é o ajuste das delimitações: área, lugar livre, com isso, ligado, unido. No Althochdeutschen (Alto-alemão antigo) ${ }^{6}$ multiplicou-se o significado. - Fala-se de um espaço que significa rûmjan entre duas paisagens, e de um verbo no sentido de "criar espaço para cultivar", como um ermo; além disso, emprega-se no sentido de 'lugar desocupado', continuamente deixando um lugar vazio, até mesmo na acepção para o verbo intransitivo "sair". Em todos os significados, - aqui não é o lugar adequado, mas -, enfatizo somente e continuamente a permanência da ideia fundamental: grande, extenso, vago; o que também é sempre nítido na delimitação à palavra expressa. Para o nosso propósito ele é importante, já

\footnotetext{
${ }^{3}$ Na obra Antropogeografia Ratzel também faz referências a muitos autores, principalmente na primeira parte do primeiro volume, em especial os capítulos 1, 2, 3, 4 e 5. Para maiores detalhes, remeto os leitores a consultarem o artigo intitulado A Filosofia na Antropogeografia de Friedrich Ratzel, publicado no periódico Caderno de Geografia/PUC-Minas, v. 24, n. 42, pp. 155-168, jul./dez., 2014. Autoria de Marquessuel Dantas de Souza. (N. T.).

${ }^{4}$ Der Raum. I Teil. 1. Kapitel: Das Wesen des Raumes, pp. 01-05. - O Espaço. $1^{\text {a }}$ Parte, capítulo 1. A essência do espaço. (N. T.).

${ }^{5}$ Dialetos germânicos do norte (Norte europeu - Escandinávia - onde se falava o dialeto germânico antigo). Grifos do tradutor. (N. T.).

${ }^{6}$ Princípio da língua alemã. Grifo do tradutor. (N. T.). 
que no Althochdeutschen o emprego da palavra espaço e tempo se dão no sentido de nossa presente "época"7. - "No espaço as luzes do dia" são fortes (intensas), para o tempo os dias são resplandecentes (ensolarados). O mesmo corresponde ao modo de pensar quanto a Schiller "no espaço de poucos séculos".

A impossibilidade de pensar o espaço de outra maneira - como infinito - já foi reconhecida na antiguidade. Quem sabe, se não temos a ideia grega da cosmogonia de Hesíodo em todas as coisas do princípio do Caos, do vazio bocejante, determinado e realizado como existência? Isto nada mais é o espaço, no qual, a terra se desenvolve, primeiramente, e em que a terra é o mar diante do céu. Esta concepção genética torna-se atrasada através dos eleatas e de Heráclito às teses filosóficas. Concluindo, apenas o vazio é capaz de limitar os seres, mas aí o vazio é inconcebível, devendo os seres ilimitados ser infinitos. E se Heráclito ensina a mudança eterna, ele também teve o espaço vazio por si mesmo. Pois que no vazio nenhuma mudança é possível.

Muito diferente é a concepção da doutrina de Kant: o espaço é a nossa forma geral de contemplação dos corpos. Ele está em nosso espírito como uma necessidade hereditária, uma sensação espacialmente ordenada. Habitualmente não há esta necessidade - com Kant -, mas para tomar uma vez por todas em certas pessoas, antes, é apropriado pensar na qualidade, do mesmo modo como em outros (ensinamentos) desenvolvidos. Este desenvolvimento pode somente ser um efeito no procedimento do mundo, assim nós não somos absolutamente forçados a aceitá-lo estando na acepção interior do conjunto desordenado em relação ao mundo. Nesta forma de concepção, se traz pelo menos a disposição espacial.

Apenas penso na instrução linguística da palavra espaço situada como prova da possibilidade de se imaginar um espaço vazio. Isto é somente uma das precipitações ou uma das informações frequentes na formação da língua. Não encontro homem que pense em ideias filosóficas intactas nem imagine objetos num recipiente vazio sob o espaço em todos os lugares do mundo, pois que um recipiente assim pertence à cerca dos confins (limites) em que ninguém pode pensar.

Sem dúvida, a ideia de espaço vazio é oposta a tendência de imaginar o espaço como algo que está fora das coisas. Somente para que o espaço não se separe do objeto, não se deixe isolar, cujo mesmo está a torna-se logo no aspecto de um espaço vazio, do desenvolver

\footnotetext{
${ }^{7}$ Referindo-se, principalmente ao século XIX e início do século XX.

${ }^{8}$ [Conferir também Friedrich Rückert no poema Barbarossa: "conforme o espaço longo, ele acenava um menino"]. (Nota do Autor). - Colchetes conforme o original. (N. T.).

Souza, 2017 ISSN 0104-5490 
atomístico jamais estável de criar raízes [o espaço vazio permanece uma abstraçao matemática] $]^{9}$.

De todos as outras características, os objetos se distinguem do espaço através daquilo que ele é em geral. Diz-se que: o espaço é perceptível (visível) e sensível, tão que, também nada vale no sentido das caraceterístcas distintas. Nunca tomamos o espaço com gradações de verdadeiras qualidades, com cores claras e escuras, tons altos e profundos e assim por diante. Percebemos e também vemos que ele não é separado dos objetos, visto que o percebemos. Como podemos notar na parte de cima, vazio nenhum representa o espaço ou nada do abstrair do conteúdo. Com efeito, quando fizemos este ensaio não imaginamos um espaço sem objetos; tanto que temos em primeriro lugar ou antes de mais nada os objetos feitos para fora ${ }^{10}$. É melhor, por conseguinte, não aplicar a palavra propriedade ao espaço. Kant tem o espaço como a forma de nossas sensações, referindo-se às coisas exteriores, formando a singularidade do espaço.

Formulamos, além disso e mais adiante, a qualidade do espaço como conceito (termo) para com o tempo, pois todo o espaço é da mesma qualidade e característica na medida em que é espaço. Deste modo, quase nenhuma palavra espaço é de espécie distinta ou de gêneros conjuntos com o espaço. - O espaço é sempre o mesmo, sua diferença localiza-se, situa-se apenas em si próprio. Simplesmente o objeto no espaço diferencia-se, não o próprio espaço. Um espaço é em si o mesmo. Daí também nos é dado o conhecimento de que qualquer espaço está, algum lugar, no entendimento de todo o espaço.

Assim como se diz do tempo objetivo, também se pode falar do espaço objetivo. Podese compreender sob aquelas condições objetivas, cuja influência do espaço nos surge como forma de contemplação subjetiva. O espaço objetivo é uma incógnita, nós só podemos aproximar-se dele enquanto elemento subjetivo exclusivo em nossas segregadas (por exemplo, a estimativa subjetiva das distâncias) observações. Ele torna-se, porém, sempre em nossa concepção, a noção abstrata à sua imagem.

Nisso, a imensidade do espaço nos é sem nenhum limite para pensarmos o raciocínio do mundo. Quão longe podemos pensar, pensamos o espacial em toda parte. Na verdade, não creio como alguns filósofos pensam, em espaços finitos (limitados), num convite sobre ir para fora e continuamente pressupor novos espaços, contudo, pode-se representar o espaço

\footnotetext{
${ }^{9}$ Colchetes conforme o original. Doravante, todos os colchetes são conforme o original. (N. T.).

${ }^{10} \mathrm{Ou}$ seja, neste ultimo trecho o autor se refere à ideia de que os objetos são o princípio do espaço. Os objetos formam a essência do espaço, os objetos constituem o espaço. Os objetos são elementos que possuem formas perceptíveis no exterior (N. T.). 
completo num dado espaço calmo e delimitado. No entanto, porque o espaço é uma forma de contemplação, jamais podemos (enquanto nós olhamos ou pensamos em olhar) chegar em sua fronteira, menos ainda além. E do mesmo modo é o tempo. Assim é a infinidade uma caraceterística indispénsável, necessária à nossa ideia de tempo e espaço. Todas as nossas cencepções, bem como os nossos entendimentos são finitos, porque tempo e espaço não são conceitos, todavia, segue disso outrossim, que eles são infinitos. Eles são formas de contemplações necessários que nunca abandonaremos.

Tempo e espaço tem em comum o que suas menores seções (trechos) reconhecem em conjunto (na totalidade). Tão breve é o ser do tempo que o avistamos espaçoso com nossas experiências, conhecendo assim todo o tempo e qualquer espaço. - Nada podemos adicionálos as descobertas. Podemos nos familiarizar com a nova era ou com as novas partes (porções) do universo (espaço), assim como a geologia, a geografia, a astronomia (terra/mundo), em períodos já descobertos que ninguém havia conhecido anteriormente. Mas todos estes são apenas o conteúdo de um novo existir: ao tempo e ao espaço não são, assim, adicionados nada de novo. Na essência do tempo e do espaço como forma de contemplação é dado que sejam Universais (absolutos), que assim sejam por toda parte, como nos é ao travar conhecimento com algum lugar.

\section{A ESSÊNCIA DO TEMPO'11}

Em cada momento o tempo "reflui". O "correr do tempo" mostra o sinal do movimento, das alterações. Ele é a relação dos objetos em seu efeito. Ele não é palpável (tangível). Ele se coloca, porém, objetivo no movimento ${ }^{12}$ subjetivo desta percepção do movimento [superior às alterações]. Sensações seguidas umas sobre as outras (sucessivamente) é, neste particular, o lado subjetivo do tempo.

Uma existência intemporal nos é inconcebível. Daí o terror (espanto) da eternidade. O tempo é contínuo, é o vínculo das manifestações, o poder de uma cadeia de particularidades. Ele não descansa, apenas repousa a consciência individual.

\footnotetext{
${ }^{11}$ Die Zeitforderung in den Entwicklungswissenschaft. II Teil. 1. Kapitel: Das Wesen der Zeit, pp. 33-35. - O Tempo. A exigência do tempo no desenvolvimento das ciências. $2^{\mathrm{a}}$ Parte, capítulo 1 . A essência do tempo. (N. T.).

${ }^{12}$ [É evidente que Ratzel pensa aqui na definição de Aristóteles: “o tempo é o número de movimento"]. (Nota do editor Paul Barth). 
A consciência da duração, do "Eu" depois associado ao agora na precedência, é o tempo $^{13}$. Ele é infinito pelo mesmo motivo que o espaço (ver acima). A infinidade não tem nenhuma fronteira, nenhuma determinação temporal. Por isso no poeta Flemming a infinidade ou mesmo a eternidade da temporalidade lhe aparece, quando ele diz: "Ah, no entanto, aquele mesmo tempo sem tempo está chegando e nos tomaria em seus tempos!”.

O tempo é engenhoso. Ele se mostra apenas como uma sucessão; o que passa, não vem contra o que acontece em um sentido determinado. Sob a confluência do brilho distante do tempo, às vezes, como outro caráter aceito. A engenhosidade desaparece na vista. A revolução (o círculo/elipse) dos satélites em torno dos planetas parece sempre o mesmo em si, um caminho (uma rota) em retroceder-se. Isto é apenas o efeito da perspectiva. Em realidade são movimentos cósmicos engenhosos em que só não vemos o pequeno ângulo. Eles não são círculos autênticos (revoluções reais), apenas espirais.

- Deve-se estar entre a localização e a duração como em uma diferente época. Um período é referência como uma primeira ou última mudança. Para localizar-se, consta melhor a consequência. Ordem e duração são dois elementos diversos. Podemos somente medir a duração. Daí ela é o nosso esforço para a transformação da ordem cronológica em duração.

Não se deve falar a partir do conceito de tempo. O tempo não é conceito, mas sim uma contemplação. Sob o conceito de "homem" eu posso ser branco, negro, grande ou pequeno que acompanha o tempo, porém, nem sou novo nem velho, nem pequeno nem grande. [A única coisa, são, antes, os conceitos a partir deles. Por exemplo, existem diferentes pessoas antes mesmo que o conceito de "homem" seja abstraído. O tempo está, no entanto, sempre pronto em nossas consciências, ele existe em si mesmo em suas únicas partes adotadas].

Passado e futuro são suas características. Estas “características”, entretanto, representam simplesmente as partes do tempo de um ponto para frente e para trás.

\footnotetext{
${ }^{13}$ [O que Ratzel visa aqui é a diferença empírica dos elementos lógicos na convicção do tempo. A sequência dos acontecimentos se dá através da mudança das sensações, porém, somente se criam variando o conteúdo do tempo. - Que este, além disso, é um mesmo e representa-se inalterado; que uma hora de tempo em Homero como tempo significa o mesmo como uma presença de hora ou do futuro distante. Não podemos mesmo tomá-lo a partir das sensações, separar apenas como unidade e identidade de nossas consciências, pois cada um de nós se baseia em acontecimentos e não entre dois subsequentes acontecimentos incomunicáveis inseridos]. O lado objetivo e subjetivo do tempo deve encontrar-se descrito no referido Paul Flemming*, em um pequeno poema didático: "Pensamentos sobre o tempo", por exemplo, nos seguintes versos:

"O tempo que morre em si testemunha também o estar fora,

Isto vem para mim e para ti, de quem você e eu...

O tempo é o que você é, e você é o tempo,

Unicamente perto, você ainda é o tempo."

(Nota do editor Paul Barth).

* Paul Fleming (1609-1640), foi um poeta alemão do período barroco. - Deve-se ressaltar que no texto original o nome do citado autor aparece conforme exposto: Paul Flemming.

$\begin{array}{lll}\text { Souza, } 2017 & \text { ISSN 0104-5490 } & 267\end{array}$
}


Não há (objetivamente) tempo vazio. O tempo é (objetivamente) somente através do seu conteúdo. Assim crê Heinrich Noë nas gotas que caem da caverna Adelsberger"14 "para perceber a pulsação do tempo". Certamente existe tempo, de cujo conteúdo nada se diz com prudência. Assim diz Kant: "quando a terra ainda estava incandescente, tanto que não existia vida...”. Este tempo é vazio, devido a nossa inconsciência. - É a tarefa da ciência, preencher gradualmente o vazio do tempo.

Cada processo está em conjunto um com o outro. O tempo é universal, e a homogeneidade do tempo exige homogeneização (uniformidade), resumindo todo tratamento nos problemas científicos. Geologia e história devem em primeiro lugar assemelharem-se (visar) e em segundo lugar devem continuar prosseguindo. Mas isto, por enquanto, ainda é um ideal. A história determina a ordem cronológica e a duração (período), a geologia, por sua vez, como veremos a seguir, se detém em geral apenas com a 'ocupação cronológica'; a pergunta sobre duração é em geral muito negligenciada e aqui alguma coisa deve ser mais bem comprovada (testada, aguçada) e estar mais nítida.

\section{REFERÊNCIAS}

RATZEL, Friedrich. Raum und Zeit in Geographie und Geologie. Naturphilosophisch Betrachtungen. (Herausgegeben von Paul Barth) Leipzig: Johann Ambrosius Barth, 1907.

\footnotetext{
${ }^{14}$ Referência às grutas de Postojna na Eslovênia. Heinrich August Noë (1835-1896) foi um escritor alemão. (N. T.). 